\title{
CRESCIMENTO DO MARACUJAZEIRO AMARELO SOB ESTRESSE SALINO E BIOFERTILIZAÇÃO EM AMBIENTE PROTEGIDO CONTRA PERDAS HÍDRICAS
}

\author{
J. L. O. Freire', L. F. Cavalcante' ${ }^{2}$, A. M. Rebequi ${ }^{3}$, T. J. Dias ${ }^{4}$ e M. S. Vieira ${ }^{5}$ \\ ${ }^{1}$ Instituto Federal do Ceará - Campus Crato \\ 2,3,4,5 Universidade Federal da Paraíba - Centro de Ciências Agrárias \\ E-mail: luciniooliveira@yahoo.com.br ${ }^{1}$, lofeca@ufpb.br ${ }^{2}$, alexrebequi@hotmail.com ${ }^{3}$, tjardelino@hotmail.com ${ }^{4}$ e \\ monti_br@yahoo.com.br ${ }^{5}$
}

RESUMO

O objetivo do trabalho foi avaliar a influência do biofertilizante bovino e cobertura morta vegetal no crescimento vegetativo do maracujazeiro amarelo irrigado com água não salina e salina em ambiente protegido contra perdas hídricas. O experimento foi conduzido no período de outubro de 2008 a abril de 2009, no município de Remígio, Paraíba. O delineamento estatístico foi em blocos casualizados, em esquema fatorial $2 \times 2 \times 2$, referente à água não salina $(0,5$

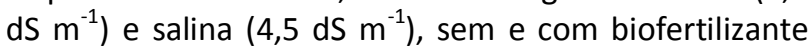
bovino, sem e com cobertura morta, com três repetições e três plantas por parcela. Avaliaram-se o período para poda do broto apical, taxa de crescimento absoluto em altura, comprimento de internódio, número de ramos produtivos e diâmetro do caule das plantas. O aumento do nível de salinidade da água, independentemente da adição do biofertilizante, inibiu o crescimento das plantas. O período do transplantio à poda do broto apical das plantas irrigadas com água salina e o uso do biofertilizante foi antecipado em 8,16 dias. O maior crescimento em altura do maracujazeiro amarelo ocorreu no solo com biofertilizante e cobertura morta.

PALAVRAS-CHAVE: salinidade, taxa de crescimento absoluto em altura, cobertura morta.

\section{GROWTH PASSION FRUIT UNDER SALINE STRESS AND BIOFERTILIZATION PROTECTED AGAINST LOSS IN WATER ENVIRONMENT}

\section{ABSTRACT}

The aim of the study was to evaluate the influence of bovine biofertilizer and plant mulch in the vegetative growth of yellow passion fruit (Passiflora edulis Sims f. flavicarpa Degener.) irrigated with non saline and saline water under protected against water loss. The experiment was conducted from October 2008 to April 2009 at Remigio, Paraiba State. The statistical design was randomized blocks in factorial $2 \times 2 \times 2$ on the non-saline $\left(0.5 \mathrm{dS} \mathrm{m}^{-1}\right)$ and saline water $\left(4.5 \mathrm{dS} \mathrm{m}^{-1}\right)$ with and without biofertilizer with and without mulch with three replications and three. We evaluated the time for pruning the apical bud, absolute growth rate in height, internodal length, number of branches and stem diameters of plants. The increased level of salinity of water, irrespective of biofertilizer addition, inhibited the growth of plants. The period from transplanting to pruning of the apical bud of plants irrigated with saline water and the use of biofertilizer was 8.16 days in advance.

KEY-WORDS: salinity, absolute growth rate in height, mulch. 


\section{CRESCIMENTO DO MARACUJAZEIRO AMARELO SOB ESTRESSE SALINO E BIOFERTILIZAÇÃO EM AMBIENTE PROTEGIDO CONTRA PERDAS HÍDRICAS}

\section{INTRODUÇÃO}

A cultura do maracujazeiro amarelo (Passiflora edulis Sims f. flavicarpa Degener) irrigado vem se destacando no contexto da fruticultura brasileira, em face da contribuição na melhoria de índices socioeconômicos no campo. O Brasil ocupa a posição de maior produtor e consumidor mundial de maracujá amarelo e a agroindústria dos seus frutos é responsável pelo agronegócio do terceiro suco mais produzido no país.

Apesar dessa expressividade, o rendimento nacional, inferior a $15 \mathrm{t} \mathrm{ha}^{-1}$, ainda é baixo com esta cultura, mas foi registrado um decréscimo na produtividade de cerca de $1 \%$ entre as safras de 2007 e 2008. No ano agrícola de 2008, com plantios convencionais em regiões fisiográficas produtoras no Estado, a Paraíba apresentou uma produtividade muito baixa $\left(8,8 \mathrm{t} \mathrm{ha}^{-1}\right)$ (IBGE, 2010).

Nas áreas produtoras de regiões semiáridas, não obstante a demanda evaporativa superar o suprimento hídrico ao solo por precipitações pluviométricas e/ou irrigações suplementares, a qualidade das águas que podem ser usadas na irrigação nem sempre é adequada, pois além da salinidade aumentar ao longo do tempo, muitas vezes, o cultivo é feito em solos que não possuem condições físicas para lixiviação dos sais com as chuvas do período das águas e aeração suficiente à expansão radicular (CAVALCANTE et al., 2006). A necessidade exige o uso inevitável dessas águas com fortes restrições à agricultura em geral, inclusive do maracujazeiro amarelo resultando em baixo desempenho produtivo da cultura pelo efeito deletério dos sais nos processos fisiológicos da germinação das sementes (MEZA et al., 2007), crescimento e demais fenofases da planta.

A classificação do maracujazeiro amarelo como planta sensível à salinidade, conforme apresentada por Ayres e Westcot (1999), diverge da literatura específica. Esses autores afirmaram que, como planta sensível à salinidade, o maracujazeiro amarelo deveria apresentar declínio produtivo quando a condutividade elétrica do ambiente radicular atingisse valores superiores a 1,3 dS $\mathrm{m}^{-1}$, entretanto, Cavalcante et al. (2002), após irrigação com água de 0,5, 1,5 e 2,5 dS m$~ m^{-1}$, Soares et al. (2002) com águas de 1,0 a $8,0 \mathrm{dS} \mathrm{m}^{-1}$, e Macedo (2006) com água de 3,6 dS $\mathrm{m}^{-1}$, concluíram que a cultura se comporta como moderadamente tolerante aos sais. Para os autores, os efeitos da salinidade da água se intensificam com a idade, onde, aos 32 e 77 dias, após a germinação, os níveis limiares foram, respectivamente, de 5,61 e 2,73 dS m ${ }^{-1}$.

Para reduzir os efeitos depressivos da salinidade da água, ou do solo, no comportamento vegetativo e produtivo do maracujazeiro amarelo, pesquisas vêm sendo implementadas com a utilização do biofertilizante bovino em conjunto com alternativas de proteção contra perdas hídricas (COLLARD et al., 2001).

Em estudos com a aplicação de biofertilizantes comum e supermagro em maracujazeiro amarelo, nas dosagens de 0,0;0,6; 1,2; 1,8 e 2,4 $\mathrm{dm}^{3}$ planta $^{-1}$, Cavalcante et al. (2007) não observaram interferência significativa no número de ramos produtivos, no período do plantio à poda do broto terminal da haste principal e dos ramos laterais.

Pelo exposto, o objetivo do trabalho foi avaliar o comportamento vegetativo do maracujazeiro amarelo submetido ao uso do biofertilizante bovino em condições de irrigação 
com água não salina e salina, em lisímetros sem e com cobertura morta, com reposição da solução drenada após cada irrigação.

\section{MATERIAL E MÉTODOS}

O experimento foi conduzido no município de Remígio, $\mathrm{PB}$, situado nas coordenadas geográficas de $6^{\circ} 53^{\prime} 00^{\prime \prime}$ de latitude Sul, $36^{\circ} 02^{\prime} 00^{\prime \prime}$ de longitude Oeste, altitude de $470 \mathrm{~m}$, inserido na Mesorregião do Agreste Paraibano e na Microrregião do Curimataú Ocidental (INTERPA, 2008), no período de outubro de 2008 a abril de 2009.

As variáveis climáticas registradas durante a realização do experimento estão apresentadas na Tabela 1, com dados de velocidade do vento e umidade relativa do ar obtidos de coletas na Estação Climatológica do Centro de Ciências Agrárias da Universidade Federal da Paraíba, Areia, $\mathrm{PB}$, distante $20 \mathrm{~km}$ da área experimental e corrigidas com base na altitude, de acordo com Doorenbos e Pruitt (1977). Os dados de temperatura média do ar foram coletados utilizando um termômetro de máxima e mínima, assim como os de evapotranspiração de referência e evaporação foram obtidos pelo método do Tanque Classe $A$, instalados na área experimental.

Tabela 1: Dados médios climáticos nos períodos distintos da execução do experimento.

\begin{tabular}{lcccccc}
\hline \multirow{2}{*}{ Variáveis climáticas } & \multicolumn{7}{c}{ Períodos } \\
\cline { 2 - 7 } & $(1)$ & $(2)$ & $(3)$ & $(4)$ & $(5)$ & $(6)$ \\
\hline Temperatura $\left({ }^{\circ} \mathrm{C}\right)$ & 23,5 & 25,3 & 25,1 & 25,5 & 23,6 & 25,2 \\
U. R. (\%) & 75,7 & 78,1 & 75,8 & 79,7 & 81,2 & 87,3 \\
Velocidade do vento $\left(\mathrm{m} \mathrm{s}^{-1}\right)$ & 3,7 & 2,1 & 2,4 & 2,9 & 2,5 & 2,1 \\
Precipitação (mm) & 0,0 & 6,6 & 0,8 & 56,1 & 140,1 & 160,1 \\
ECA (mm dia $\left.{ }^{-1}\right)$ & 7,5 & 7,1 & 7,7 & 7,2 & 5,7 & 6,1 \\
\hline ET $_{0}\left(\mathrm{~mm} \mathrm{dia}^{-1}\right)$ & 5,2 & 5,3 & 5,8 & 5,4 & 4,3 & 4,6 \\
\hline
\end{tabular}

U. R. = umidade relativa do ar; ECA = evaporação no tanque Classe A; ET0 = evapotranspiração de referência; (1): 13 de outubro a 11 de novembro de 2008; (2): 12 de novembro a 11 de dezembro de 2008; (3): 12 de dezembro de 2008 a 10 de janeiro de 2009; (4): 11de janeiro a 9 de fevereiro de 2009; (5): 10 de fevereiro a 11 de março de 2009; (6): 12 de março a 4 de abril de 2009.

O substrato constou de uma mistura dos primeiros $10 \mathrm{~cm}$ de um Argissolo Amarelo distrófico não salino (SANTOS et al., 2006) com esterco bovino, com atributos químicos e físicos indicados na Tabela 2 e determinados no Laboratório de Fertilidade, Química e Física do Solo, do Departamento de Solos e Engenharia Rural do Centro de Ciências Agrárias, Universidade Federal da Paraíba, Areia, PB, utilizando as metodologias empregadas pela Embrapa (1997). 
Tabela 2: Resultados analíticos do substrato (solo + esterco bovino) utilizado nas unidades experimentais.

\begin{tabular}{|c|c|c|c|}
\hline Atributos Químicos & Valores & Atributos Físicos & Valores \\
\hline pH (água: 1:2,5) & 8,6 & Areia $\left(\mathrm{g} \mathrm{kg}^{-1}\right)$ & 808 \\
\hline$P\left(m g d m^{-3}\right)$ & 103 & Silte $\left(\mathrm{g} \mathrm{kg}^{-1}\right)$ & 110 \\
\hline $\mathrm{K}^{+}\left(\mathrm{mg} \mathrm{dm}^{-3}\right)$ & 607 & Argila $\left(\mathrm{g} \mathrm{kg}^{-1}\right)$ & 82 \\
\hline $\mathrm{Ca}^{+2}\left(\mathrm{cmol}_{\mathrm{c}} \mathrm{dm}^{-3}\right)$ & 2,65 & Ada $\left(\mathrm{g} \mathrm{kg}^{-1}\right)$ & 33 \\
\hline $\mathrm{Mg}^{+2}\left(\mathrm{cmol}_{\mathrm{c}} \mathrm{dm}^{-3}\right)$ & 0,57 & GF (\%) & 67 \\
\hline $\mathrm{Na}^{+}\left(\mathrm{cmol}_{\mathrm{c}} \mathrm{dm}^{-3}\right)$ & 1,91 & ID (\%) & 33 \\
\hline $\mathrm{SB}\left(\mathrm{cmol}_{\mathrm{c}} \mathrm{dm}^{-3}\right)$ & 6,68 & $\mathrm{D}_{\mathrm{s}}\left(\mathrm{Mg} \mathrm{m}^{-3}\right)$ & 1,32 \\
\hline $\mathrm{H}^{+}+\mathrm{Al}^{+3}\left(\mathrm{cmol}_{\mathrm{c}} \mathrm{dm}^{-3}\right)$ & 1,29 & $\mathrm{D}_{\mathrm{p}}\left(\mathrm{Mg} \mathrm{m}^{-3}\right)$ & 2,64 \\
\hline $\mathrm{Al}^{+3}\left(\mathrm{cmol}_{\mathrm{c}} \mathrm{dm}^{-3}\right)$ & Ausente & $P_{t}\left(m^{-3}\right)$ & 0,50 \\
\hline $\operatorname{CTC}\left(\mathrm{cmol}_{\mathrm{C}} \mathrm{dm}^{-3}\right)$ & 7,97 & $\mathrm{~A} / \mathrm{S}$ & 0,75 \\
\hline M.O. $\left(\mathrm{g} \mathrm{kg}^{-1}\right)$ & 11,81 & Classe textural & $A F$ \\
\hline
\end{tabular}

$\mathrm{SB}=$ Soma de bases $\left(\mathrm{Ca}^{2+}+\mathrm{Mg}^{2+}+\mathrm{Na}^{+}+\mathrm{K}^{+}\right) ; \mathrm{CTC}=$ Capacidade de troca catiônica $\left[\mathrm{SB}+\left(\mathrm{H}^{+}+\right.\right.$ $\left.\left.\mathrm{Al}^{3+}\right)\right] ; \mathrm{M} . \mathrm{O}=$ Matéria orgânica; Ada = Argila dispersa em água; GF = Grau de floculação; ID = Índice de dispersão; $D_{s}=$ Densidade do solo; $D_{p}=$ Densidade de partícula, $\mathrm{P}_{\mathrm{t}}=$ Porosidade total; $\mathrm{A} / \mathrm{S}=$ Relação argila/silte; $\mathrm{AF}=$ Areia franca.

O experimento, tendo o maracujazeiro amarelo (Passiflora edulis f. flavicarpa Degener) como planta-teste, foi instalado em blocos casualizados em esquema fatorial $2^{3}$, referente aos tratamentos com águas salina e não salina, sem e com biofertilizante bovino comum, sem e com cobertura morta, com três repetições e três plantas por parcela, totalizando 72 unidades experimentais. Os tratamentos analisados foram: $T_{1}: A_{1} B_{1} C_{1}$ (água não salina, sem biofertilizante, sem cobertura morta); $T_{2}: A_{1} B_{1} C_{2}$ (água não salina, sem biofertilizante, com cobertura morta); $T_{3}$ : $A_{1} B_{2} C_{1}$ (água não salina, com biofertilizante, sem cobertura morta); $T_{4}: A_{1} B_{2} C_{2}$ (água não salina, com biofertilizante, com cobertura morta); $T_{5}: A_{2} B_{1} C_{1}$ (água salina, sem biofertilizante, sem cobertura morta); $T_{6}: A_{2} B_{1} C_{2}$ (água salina, sem biofertilizante, com cobertura morta); $T_{7}: A_{2} B_{2} C_{1}$ (água salina, com biofertilizante, sem cobertura morta); $T_{8}: A_{2} B_{2} C_{2}$ (água salina, com biofertilizante, com cobertura morta).

A irrigação foi feita com água não salina (CE de $0,5 \mathrm{dS} \mathrm{m}^{-1}$ ) e água salina (CE de $4,5 \mathrm{dS} \mathrm{m}^{-1}$ ), com frequência de aplicação de sete dias e fração de lixiviação correspondente a $10 \%$ do volume hídrico aplicado. Diariamente, procedeu-se a reposição da lâmina de irrigação correspondente a $20 \%$ da evaporação medida no Tanque Classe A. Após cada irrigação, efetuou-se a reposição da solução drenada.

O biofertilizante foi preparado em partes iguais de esterco bovino fresco misturado com água não salina e não clorada, na proporção de 1:1 (100 litros de cada componente), em recipiente hermeticamente fechado por um período de 30 dias, conforme sugestões de Santos e 
Akiba (1996), a partir da fermentação anaeróbica. Para a liberação do gás metano produzido pela fermentação, foi conectada uma mangueira fina na parte superior do biodigestor, mantendo a outra submersa em um recipiente com água para impedir a entrada de ar.

Depois de diluído em água na proporção de 1:1, o biofertilizante bovino foi aplicado às covas uma semana antes e a cada 90 dias, em volume equivalente a uma alíquota de $10 \mathrm{dm}^{3}$ por planta. Cada cova correspondeu à metade de uma bombona plástica, que serviu de lisímetro, com diâmetro de 0,58 m, altura de 0,50 m, com capacidade para $130 \mathrm{dm}^{3}$. Na parte inferior do lisímetro, acondicionaram-se camadas de $2,5 \mathrm{~cm}$ de brita zero e $5 \mathrm{~cm}$ de areia de rio lavada. $\mathrm{Na}$ parte inferior do lisímetro, para lixiviação da solução excedente e manutenção do ambiente edáfico em capacidade de campo após cada irrigação, foram perfurados dois drenos, equidistanciados, com $1 \mathrm{~cm}$ de diâmetro.

Em cada lisímetro foi acondicionada uma mistura do material de solo dos $10 \mathrm{~cm}$ superficiais juntamente com 10\% em volume de esterco bovino de relação C/N 16:1.

A Tabela 3 dispõe as composições químicas do biofertilizante bovino e das águas de irrigação empregados no experimento, analisados conforme Richards (1954) e Embrapa (2011).

Tabela 3: Composição química do biofertilizante bovino e das águas utilizadas nas irrigações do maracujazeiro amarelo.

\begin{tabular}{cccc}
\hline Atributos Químicos & Biofertilizante & $\mathrm{A}_{1}$ & $\mathrm{~A}_{2}$ \\
\hline $\mathrm{pH}$ & 6,52 & 6,44 & 7,55 \\
$\mathrm{C} . \mathrm{E} .\left(\mathrm{dS} \mathrm{m}{ }^{-1} \mathrm{a} 25^{\circ} \mathrm{C}\right)$ & 2,72 & 0,50 & 4,50 \\
$\mathrm{RAS}\left(\mathrm{mmol} \mathrm{L}^{-1}\right)$ & 3,19 & 2,12 & 13,26 \\
$\mathrm{Ca}^{2+}\left(\mathrm{mmol}_{\mathrm{c}} \mathrm{L}^{-1}\right)$ & 4,19 & 1,67 & 2,80 \\
$\mathrm{Mg}^{2+}\left(\mathrm{mmol}_{\mathrm{c}} \mathrm{L}^{-1}\right.$ & 6,91 & 0,81 & 8,90 \\
$\mathrm{~K}^{+}\left(\mathrm{mmol}_{\mathrm{c}} \mathrm{L}^{-1}\right)$ & 0,63 & 0,11 & 0,43 \\
$\mathrm{Na}^{+}\left(\mathrm{mmol}_{\mathrm{c}} \mathrm{L}^{-1}\right)$ & 7,52 & 31,96 \\
$\mathrm{SO}_{4}{ }^{2-}\left(\mathrm{mmol}_{\mathrm{c}} \mathrm{L}^{-1}\right)$ & 12,45 & 0,86 & 0,26 \\
$\mathrm{CO}_{3}{ }^{2-}\left(\mathrm{mmol}_{\mathrm{c}} \mathrm{L}^{-1}\right)$ & $\mathrm{Ausente}$ & $\mathrm{Ausente}$ & 0,10 \\
$\mathrm{HCO}_{3}{ }^{-}\left(\mathrm{mmol}_{\mathrm{C}} \mathrm{L}^{-1}\right)$ & 1,37 & 1,12 & 3,20 \\
$\mathrm{Cl}^{-}\left(\mathrm{mmol}_{\mathrm{c}} \mathrm{L}^{-1}\right)$ & 14,11 & 3,14 & 40,80 \\
$\mathrm{Classificação}^{2}$ & $\mathrm{C}_{3} \mathrm{~S}_{1}$ & $\mathrm{C}_{1} \mathrm{~S}_{1}$ & $\mathrm{C}_{4} \mathrm{~S}_{1}$ \\
\hline
\end{tabular}

C.E. = Condutividade elétrica; RAS = Razão de adsorção de sódio $\left[\mathrm{Na}^{+} /\left(\mathrm{Ca}^{2+}+\mathrm{Mg}^{2+} / 2\right)^{1 / 2}\right] ; \mathrm{A}_{1}=$ Água não salina ; $A_{2}=$ Água salina.

A cobertura morta vegetal foi feita com uma camada de $8 \mathrm{~cm}$ de capim braquiária (Brachiaria decumbens L.) em toda área do recipiente com a planta.O plantio das mudas do maracujazeiro amarelo foi feito em arranjo espacial de 3,0 $\mathrm{m} \times 3,0 \mathrm{~m}$, usando-se o sistema de sustentação em espaldeira com um arame liso $n^{\circ} 12$, instalado a 2,0 m da superfície do solo. 
Antecedendo o plantio, fez-se a caracterização e padronização das mudas pelo mesmo número de folhas e altura. A poda do broto terminal se deu quando este ultrapassou $10 \mathrm{~cm}$ da espaldeira. A poda dos ramos laterais ou secundários foi procedida quando ambos atingiram $1,5 \mathrm{~m}$ de distância da haste principal. A adubação de fundação foi feita com $150 \mathrm{~g}$ de superfosfato simples $\left(20 \% \mathrm{P}_{2} \mathrm{O}_{5}\right)$ por planta. $\mathrm{O}$ nitrogênio e o potássio foram aplicados mensalmente em cobertura, fornecendo-se $30 \mathrm{~g}$ de uréia $(45 \% \mathrm{~N})$ e $50 \mathrm{~g}$ de cloreto de potássio $\left(58 \% \mathrm{~K}_{2} \mathrm{O}\right)$ por planta e por adubação.

As variáveis analisadas foram o diâmetro do caule, período para poda do broto apical, crescimento em altura para a avaliação da taxa de crescimento absoluto em altura, comprimento de internódio e número de ramos produtivos. A altura das plantas foi medida semanalmente com uma trena milimetrada, tomando-se como base o coleto destas na superfície do solo e o ápice caulinar. O diâmetro caulinar das plantas foi medido com um paquímetro de precisão digital Digmess à altura de $10 \mathrm{~cm}$ do coleto. A taxa de crescimento absoluto em altura foi determinada através da Equação 1, adaptada de Benincasa (2003).

$\operatorname{TCA}=\left(\mathbf{h}_{\mathbf{f}}-\mathbf{h}_{\mathbf{i}}\right) *\left(\Delta_{\mathbf{t}}\right)^{-1}$

equação (1)

TCA = taxa de crescimento absoluto em altura $\left(\mathrm{cm} \mathrm{dia}^{-1}\right) ; h_{f}=$ altura final da planta $(\mathrm{cm}) ; h_{i}$ $=$ altura da muda no dia do transplantio $(\mathrm{cm}) ; \Delta_{\mathrm{t}}=$ espaço temporal decorrido entre o dia do transplantio e da leitura da $h_{f}$ (dias).

Os resultados obtidos foram submetidos às análises de variância pelo teste $F$, com comparações de médias pelo teste de Tukey (BANZATTO e KRONKA, 2006; ASSISTAT, 2010).

\section{RESULTADOS E DISCUSSÃO}

Conforme indicado na Figura 1, não houve diferença significativa para o período do transplantio à poda do broto apical quando se utilizou água não salina $\left(0,5 \mathrm{dS} \mathrm{m}^{-1}\right)$, independentemente da adição do biofertilizante bovino. Nos tratamentos sem o insumo, o aumento da salinidade da água de irrigação inibiu o crescimento das plantas, retardando o período de poda do broto apical em 12,16 dias. Com o uso do biofertilizante, na mesma condição de acréscimo da salinidade da água de irrigação, o comportamento das plantas foi diferente, com o período da poda sendo reduzido em 5 dias.

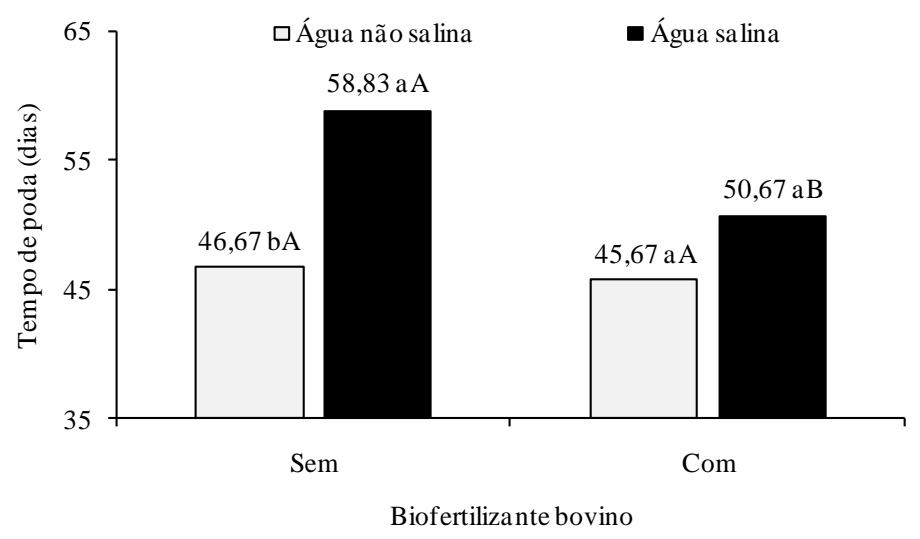


Figura 1 - Período do transplantio à poda do broto apical do maracujazeiro amarelo sob irrigação com águas de baixa e alta salinidade no solo sem e com biofertilizante bovino (DMS = 4,39).

Médias seguidas de mesmas letras minúsculas entre diferentes condições de salinidade da água dentro da mesma condição de uso de biofertilizante bovino e letras maiúsculas entre mesma condição de salinidade da água dentro de diferentes condições de uso de biofertilizante bovino, não diferem estatisticamente entre si pelo teste de Tukey $(P \leq 0,05)$.

$\mathrm{Na}$ irrigação com água salina, a adição do biofertilizante bovino estimulou o crescimento das plantas em altura, resultando em menor período para a poda do broto terminal em 8,16 dias. Com isso, evidencia-se o efeito positivo do insumo sobre o crescimento inicial das plantas com o aumento do nível de salinidade da água de irrigação. Esses resultados são concordantes com os obtidos por Campos et al. (2008), nos quais a adição desse insumo diminuiu em sete dias o tempo de poda da haste principal, mas, inferiores à variação de 59 a 63 dias observada por Cavalcante et al. (2007) após utilizarem o mesmo tipo de insumo.

Os resultados referentes à irrigação com água de baixa salinidade evidenciaram que não houve diferença significativa na taxa de crescimento absoluto em altura do maracujazeiro amarelo entre os tratamentos sem e com biofertilizante (Figura 2).

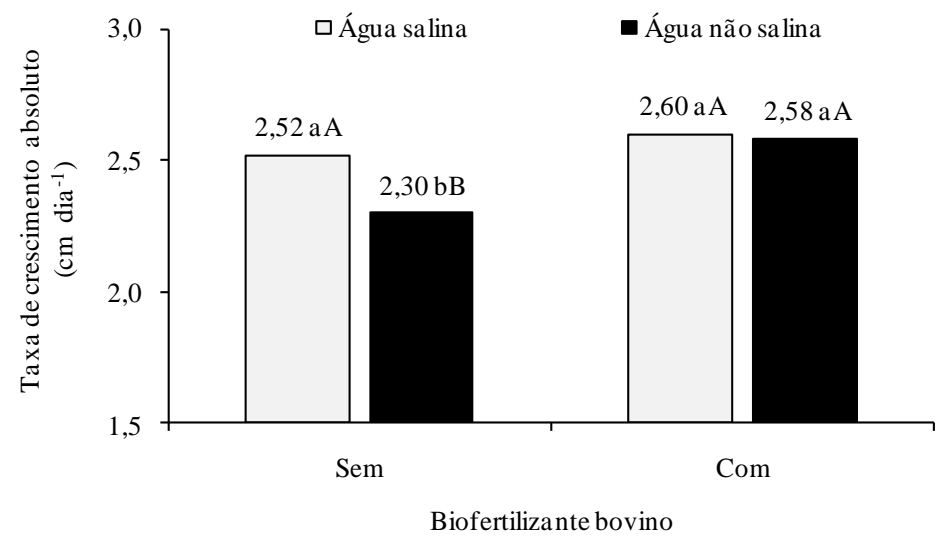

Figura 2 - Taxa de crescimento absoluto em altura do maracujazeiro amarelo submetido à salinidade da água de irrigação e uso de biofertilizante (DMS $=0,15$ ).

Médias seguidas de mesmas letras minúsculas entre diferentes condições de salinidade da água dentro da mesma condição de uso de biofertilizante bovino e letras maiúsculas entre mesma condição de salinidade da água dentro de diferentes condições de uso de biofertilizante bovino, não diferem estatisticamente entre si pelo teste de Tukey $(P \leq 0,05)$.

As plantas irrigadas com água de alta salinidade no solo e sem o biofertilizante sofreram uma redução de crescimento na ordem de $8,73 \%$ em comparação com as irrigadas com água não salina, evidenciando, conforme Correa (2005), Lima et al. (2007) e Farias et al. (2009), que os efeitos dos sais sobre as plantas podem ser causados pela diminuição na permeabilidade da água no sistema radicular, antecipando diariamente o fechamento dos estômatos, resultando em menor eficiência fotossintética, resultando em menor taxa de crescimento e de matéria seca. 
Os efeitos prejudiciais da salinidade no crescimento das plantas têm sido referenciados mais do ponto de vista tóxico dos íons, principalmente $\mathrm{Na}^{+}, \mathrm{Cl}^{-}$ou $\mathrm{SO}_{4}{ }^{2-}$ com prejuízos nas funções dos sistemas enzimáticos e síntese protéica (ZHU, 2001; WAHOME et al., 2001; GARCIA-SANCHEZ et al., 2002). Entretanto, esses efeitos podem ser também de natureza osmótica, resultando em estresse hídrico, reduzindo a água disponível às plantas, causando redução no alongamento celular, na abertura estomática, assimilação líquida de $\mathrm{CO}_{2}$, declínio da eficiência fotossintética e, consequentemente, no crescimento das plantas (LACERDA et al., 2001; MUNNS, 2002; LACERDA et al., 2003). Costa et al. (2005) e Cruz et al. (2006) observaram que o crescimento de plântulas de maracujazeiro amarelo foi significativamente inibido pelo acréscimo dos níveis de salinidade da água de irrigação.

A adição do biofertilizante proporcionou aumento da taxa de crescimento absoluto em altura quando se procedeu à irrigação com água não salina, indicando eficiência do insumo na atenuação dos efeitos danosos da salinidade e favorecendo o crescimento inicial do maracujazeiro amarelo. Os resultados indicam que o uso deste insumo na interação com água salina proporcionou um aumento de $12,17 \%$ na taxa de crescimento absoluto em altura, em relação ao solo sem o mesmo.

Nas covas sem cobertura morta, o crescimento das plantas não diferiu entre os tratamentos sem e com biofertilizante bovino (Figura 3). Por outro lado, o insumo estimulou o crescimento do maracujazeiro amarelo no solo com cobertura morta, proporcionando um aumento de $0,44 \mathrm{~cm} \mathrm{dia}{ }^{-1}$ nesta variável. De acordo com Freire et al. (2010), provavelmente, essas condições mais adequadas ao crescimento das plantas, sejam decorrentes da melhoria física do ambiente edáfico, o que resultou em maior disponibilidade de nutrientes para as plantas, maior atividade microbiana promovida, além da conservação da umidade e da temperatura do solo proporcionada pela cobertura morta.

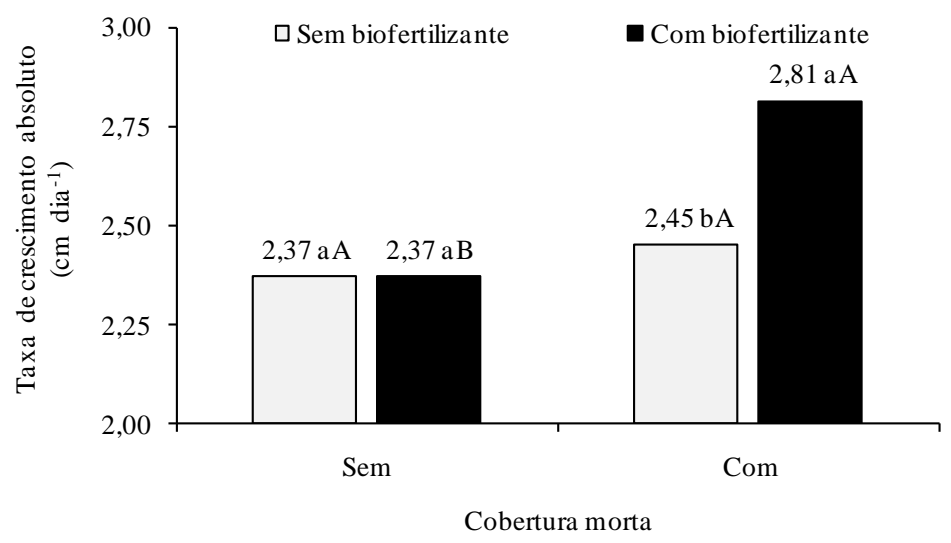

Figura 3 - Taxa de crescimento absoluto em altura do maracujazeiro amarelo submetido ao uso de biofertilizante e de cobertura morta (DMS $=0,15$ ).

Médias seguidas de mesmas letras minúsculas entre diferentes condições de uso de cobertura morta dentro da mesma condição de uso de biofertilizante bovino e letras maiúsculas entre mesma condição de cobertura morta dentro de diferentes condições de uso de biofertilizante bovino, não diferem estatisticamente entre si pelo teste de Tukey $(P \leq 0,05)$.

O diâmetro caulinar do maracujazeiro amarelo foi influenciado significativamente pela interação salinidade da água $x$ biofertilizante. Independentemente do tipo de água, observa-se 
que a adição do biofertilizante inibiu o crescimento das plantas pelo diâmetro caulinar (Figura 4). A amplitude de 12,28 a 14,65 mm foi inferior ao registrado por Campos et al. (2008) e Rodolfo Junior et al. (2009), porém, superior aos $11,2 \mathrm{~mm}$ observados por Silva (2000) e os 9,5 mm apresentados por Cavalcante et al. (2004) e similar ao verificado por Santos (2001).

Os aumentos de 13,16 para $14,65 \mathrm{~mm}$ e de 12,28 para $12,41 \mathrm{~mm}$ expressam incrementos de $11,32 \%$ e de pouco mais de $1 \%$, respectivamente, entre os diâmetros dos caules das plantas, decorrentes da irrigação com água salina em relação à irrigação com água de boa qualidade no solo sem e com biofertilizante. Essa situação difere da grande maioria dos resultados da literatura (Santos, 2001; Costa et al., 2005; Cruz et al., 2006, e Sousa et al., 2008) em que o aumento do teor salino da água de irrigação compromete o crescimento do maracujazeiro amarelo, como também, para esta variável, dos obtidos por Silva et al. (2007), Sousa et al. (2008) e Campos e Cavalcante (2009) ao concluírem que a adição do biofertilizante exerce ação atenuadora da salinidade da água de irrigação às plantas.

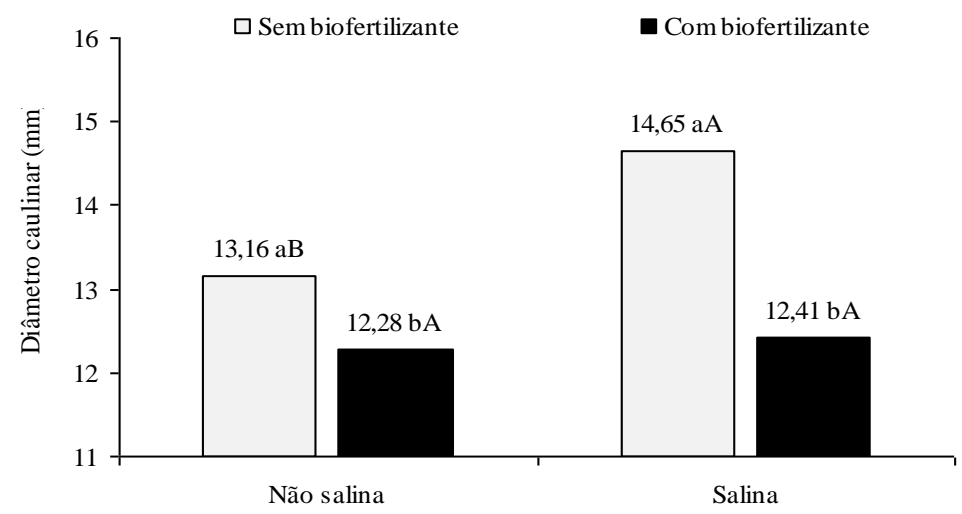

Figura 4 - Diâmetro caulinar do maracujazeiro amarelo em função da salinidade da água de irrigação e o uso de biofertilizante bovino (DMS $=0,5$ ).

Médias seguidas de mesmas letras minúsculas entre diferentes condições de uso de biofertilizante bovino dentro da mesma condição de salinidade da água e letras maiúsculas entre mesma condição de uso de biofertilizante bovino dentro de diferentes condições de salinidade da água, não diferem estatisticamente entre si pelo teste de Tukey $(P \leq 0,05)$.

Para comprimento dos internódios, os resultados indicam diferenças significativas entre os tratamentos com água não salina e salina, tanto na ausência como na presença do biofertilizante (Figura 5). Sem o uso do biofertilizante, a irrigação com água não salina proporcionou um acréscimo no comprimento de internódios de $0,67 \mathrm{~cm}$ em comparação com a irrigação com água salina. Com a utilização do insumo, o comprimento internodal foi $0,54 \mathrm{~cm}$ maior em plantas irrigadas com água não salina. A utilização do biofertilizante quando se irrigou com água salina atenuou os efeitos depressivos dos sais no crescimento do maracujazeiro amarelo e propiciou um maior comprimento de internódios. 


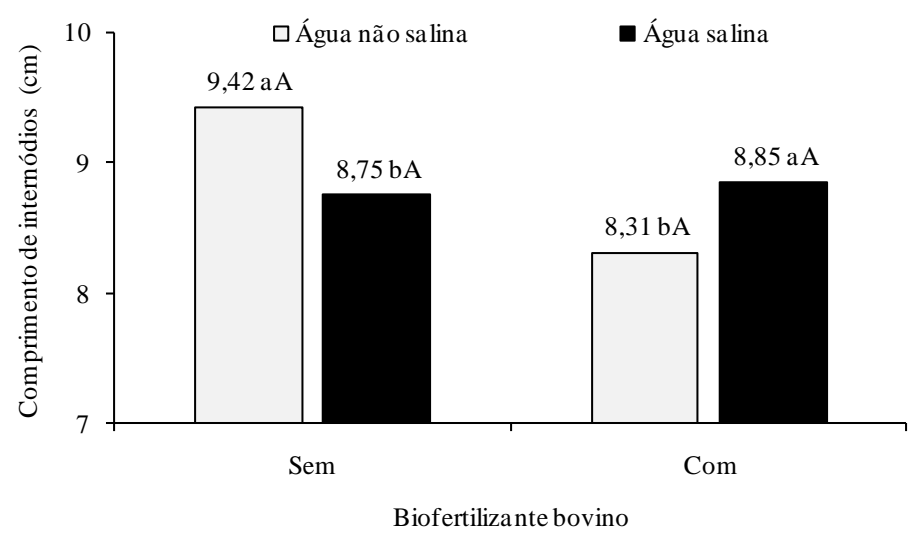

Figura 5 - Comprimento dos internódios de plantas de maracujazeiro amarelo em função da salinidade da água de irrigação e o uso de biofertilizante bovino (DMS $=0,53$ ).

Médias seguidas de mesmas letras minúsculas entre diferentes condições de salinidade da água dentro da mesma condição de uso de biofertilizante bovino e letras maiúsculas entre mesma condição de salinidade da água dentro de diferentes condições de uso de biofertilizante bovino, não diferem estatisticamente entre si pelo teste de Tukey $(P \leq 0,05)$.

$\mathrm{Na}$ análise da variável número de ramos produtivos, observa-se que a adição do biofertilizante bovino estimulou o crescimento do maracujazeiro amarelo nas duas condições de uso da água de irrigação (Figura 6). No tratamento com água não salina, a interação com o efluente orgânico possibilitou um acréscimo de cerca de $9 \%$ na quantidade de ramos produtivos,

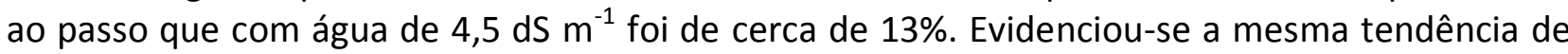
efeitos positivos do biofertilizante observada para tempo de poda do broto apical e taxa de crescimento absoluto das plantas.

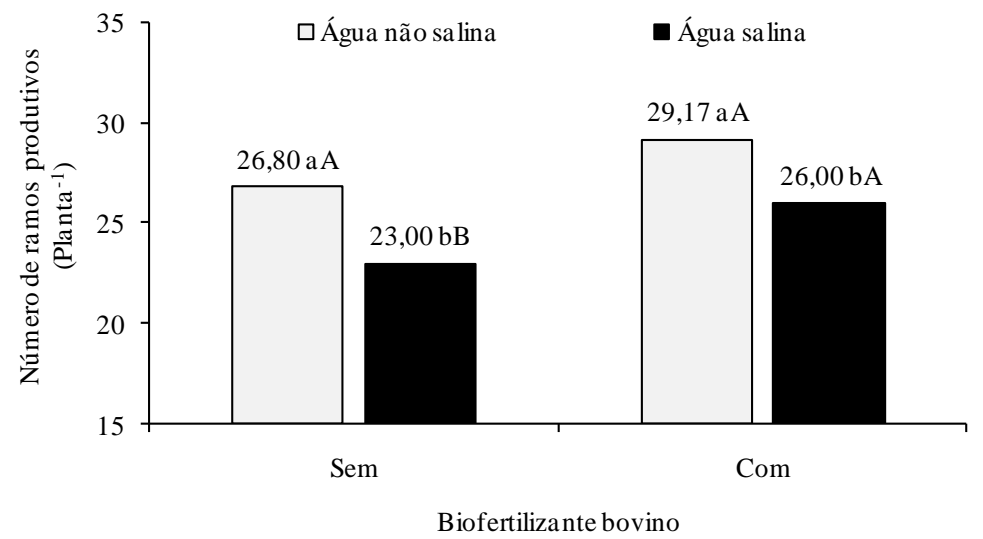

Figura 6 - Número de ramos produtivos do maracujazeiro amarelo aos 180 dias de idade na interação salinidade da água $x$ biofertilizante bovino (DMS = 2,83).

Médias seguidas de mesmas letras minúsculas entre diferentes condições de salinidade da água dentro da mesma condição de uso de biofertilizante bovino e letras maiúsculas entre mesma condição de salinidade da água dentro de diferentes condições de uso de biofertilizante bovino, não diferem estatisticamente entre si pelo teste de Tukey $(P \leq 0,05)$. 
Pela Figura 7, constata-se, no tratamento sem cobertura, comportamento invertido com relação ao uso do biofertilizante. No tratamento sem cobertura morta, o insumo estimulou em cerca de $11 \%$ a emissão de ramos produtivos e, com cobertura, inibiu em $10 \%$ o número de ramos produtivos. Essa mesma tendência foi observada por Campos et al. (2008), ressaltando a hipótese de que o biofertilizante bovino possibilita uma maior atividade microbiana no ambiente edáfico, resultando em maior competição nutricional, com reflexos negativos no crescimento das plantas, como também para o diâmetro caulinar.

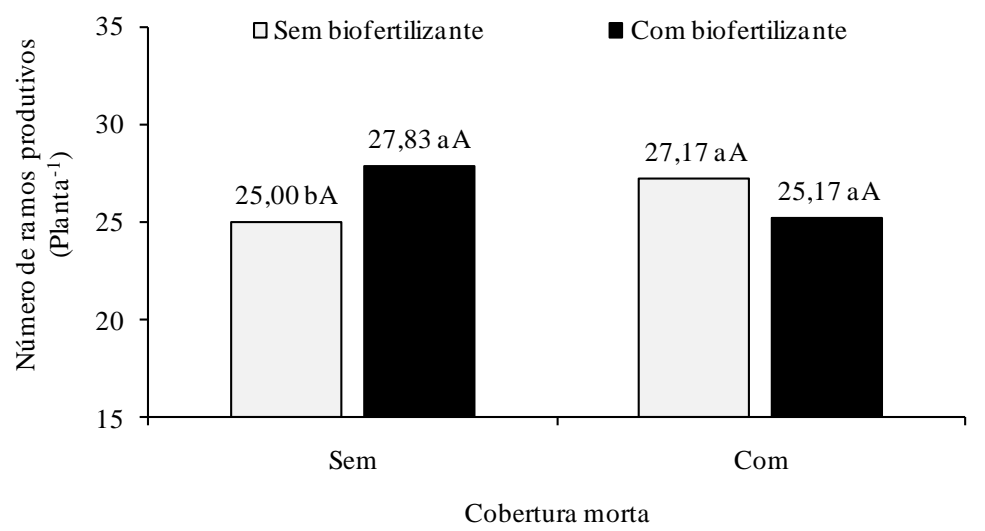

Figura 7 - Número de ramos produtivos do maracujazeiro amarelo aos 180 dias de idade na interação biofertilizante bovino $x$ cobertura morta (DMS $=\mathbf{2 , 8 0}$ ).

Médias seguidas de mesmas letras minúsculas entre diferentes condições de uso de cobertura morta dentro da mesma condição de uso de biofertilizante bovino e letras maiúsculas entre mesma condição de cobertura morta dentro de diferentes condições de uso de biofertilizante bovino, não diferem estatisticamente entre si pelo teste de Tukey $(P \leq 0,05)$.

\section{CONCLUSÕES}

O aumento da salinidade da água, independentemente da adição do biofertilizante, inibiu o crescimento das plantas.

O biofertilizante bovino estimulou o crescimento da haste principal do maracujazeiro amarelo reduzindo o período do transplantio à poda do broto apical das plantas irrigadas com água salina em 8,16 dias e promovendo uma maior taxa de crescimento absoluto nas plantas irrigadas com água de menor salinidade.

O maior crescimento em altura do maracujazeiro amarelo ocorreu no solo com biofertilizante e cobertura morta.

\section{REFERÊNCIAS BIBLIOGRÁFICAS}

1. ASSISTAT. Assistência estatística 7,5 beta. Campina Grande: UFCG. 2010.DATAR, M.T., BHARGAVA, D.S. Effects of environmental factors on nitrification during aerobic digestion of activated sludge. Journal of the Institution of Engineering (India), Part EN: Environmental Engineering Division, v.68, n.2, p.29-35, Feb. 1988.

2. AYERS, R. S.; WESTCOT, D.W. A qualidade da água na agricultura. Campina Grande: UFPB. Tradução: GHEYI, H. R.; MEDEIROS, J. F.; DAMASCENO, F. A. V. (Estudos FAO: Irrigação e Drenagem, 29), 1999. 153 p. 
3. BANZATTO, D. A.; KRONKA, S. N. Experimentação agrícola. Jaboticabal: Funep, 2006, 237 p.

4. BENINCASA, M. M. P. Análise de crescimento de plantas: noções básicas. $2^{\mathrm{a}}$ ed. Jaboticabal: Funep. 2003. 41 p.

5. CAMPOS, V. B.; CAVALCANTE, L. F.; MORAIS, T. A.; MENEZES JUNIOR, J. C.; PRAZERES, S. S. Potássio: biofertilizante bovino e cobertura do solo: efeito no crescimento do maracujazeiroamarelo. Revista Verde de Agroecologia e Desenvolvimento Sustentável, v. 1, n. 3, p. 78-86, 2008.

6. CAMPOS, V. B.; CAVALCANTE, L. F. Salinidade da água e biofertilizante bovino: efeito sobre a biometria do pimentão. Holos, v. 2, p. 10-20, 2009.

7. CAVAlCANTE, L. F.; SANTOS, G. D.; OliVEIRA, F. A.; CAVALCANTE, I. H. L.; GONDIM, S. C.; CAVALCANTE, M. Z. B. Crescimento e produção do maracujazeiro amarelo em solo de baixa fertilidade tratado com biofertilizantes líquidos. Revista Brasileira de Ciências Agrárias, v. 12, n. 1, p. 15-19, 2007.

8. CAVALCANTE, L. F.; ANDRADE, R.; COSTA, J. R. M.; CAVALCANTE, I. H. L.; GONDIM, S. C.; LIMA, E. M. de; MACEDO, J. P. da S.; SANTOS, J. B. dos; SANTOS, C. J. O. Maracujá-amarelo e salinidade. In: CAVALCANTE, L. F.; LIMA, E. M. de (ed.). Algumas frutíferas tropicais e a salinidade. Jaboticabal: Funep, 2006, p. 91-114

9. CAVALCANTE, L. F.; SILVA, P. S. V. L; SANTOS, G. D.; MESQUITA, E. F.; ALVES, G. S.; CAVALCANTE, I. H. L.; GONDIM, S. C.; OLIVEIRA, A. P. Crescimento do maracujazeiro-amarelo em substrato envasado com aplicação de biofertilizante bovino. Anais do Curso de PósGraduação em Manejo de Solo e Água, Areia, v. 26, p. 51-71, 2004.

10. CAVALCANTE, L. F.; SANTOS, J. B.; SANTOS, C. J. O.; FEITOSA FILHO, J. A.; LIMA, E. M.; CAVALCANTE, I. H. L. Germinação de sementes e crescimento inicial de maracujazeiros irrigados com água salina em diferentes volumes de substrato. Revista Brasileira de Fruticultura, v. 24, n. 3, p. 748-751. 2002.

11. COLLARD, F. H.; ALMEIDA, A.; COSTA, M. C. R. ROCHA, M. C. Efeito do uso de biofertilizante agrobio na cultura do maracujazeiro-amarelo (Passiflora edulis f. flavicarpa Deg.), Revista Biociência, v.7, n.1, p.36-43. 2001.

12. CORREIA, K. G. Índices fisiológicos de amendoim sob estresse salino. Campina Grande, 2005. Dissertação de mestrado em Engenharia Agrícola - Centro de Ciências e Tecnologia, Universidade Federal de Campina Grande, 2005.

13. COSTA, E. G.; CARNEIRO, P. T.; SOARES, F. A. L.; FERNANDES, P. D.; GHEYI, H. R.; CAVALCANTE, L. F. Crescimento inicial do maracujazeiro amarelo sob diferentes tipos e níveis de salinidade da água de irrigação. Revista Brasileira de Engenharia Agrícola e Ambiental, v. 9 (Suplemento), p. 242-247, 2005.

14. CRUZ, J. L.; PELACANI, C. R.; COELHO, E. F.; CALDAS, R. C.; ALMEIDA, A. Q.; QUEIROZ, J. R. Influência da salinidade sobre o crescimento, absorção e distribuição de sódio, cloro e macronutrientes em plântulas de maracujazeiro-amarelo. Bragantia, v.65, n.2, p.275-284, 2006.

15. DOORENBOS, J.; PRUITT, W. O. Crop water requirement. Irrigation and Drainage. Roma: FAO, 1977. 144 p. (FAO, Paper 24).

16. EMBRAPA. Serviço Nacional de Levantamento e Conservação de Solos. Manual de métodos de análise de solo. $3^{\mathrm{a}}$ Ed. Atualizada. Rio de Janeiro: EMBRAPA-SNLCS, 2011. 230 p. 
17. FARIAS, S. G. G.; SANTOS, D. R.; FREIRE, A. L. O.; SILVA, R. B. Estresse salino no crescimento inicial e nutrição mineral de gliricídia (Gliricidia sepiumi Jack Kunth ex Steud) em solução nutritiva. Revista Brasileira de Ciência do Solo, v. 33, p. 1499-1505, 2009.

18. FREIRE, J. L. O.; CAVALCANTE, L. F.; REBEQUI, A. M.; NUNES, J. C.; DIAS, T. J.; CAVALCANTE, I. H. L. Atributos qualitativos do maracujá amarelo produzido com água salina, biofertilizante e cobertura morta no solo. Revista Brasileira de Ciências Agrárias, v. 5, n. 1, p. 102-110, 2010.

19. GARCIA-SANCHEZ, F.; JIFON, J. L.; CARVAJAL, M.; SYVERTSEN, J. P. Gas exchange, chlorophyll and nutrient contents in relation to $\mathrm{Na}^{+}$and $\mathrm{Cl}^{-}$accumulation in Sunburst mandarin grafted on different Rootstocks. Plant Science, v. 162, p. 705-712, 2002.

20. INSTITUTO BRASILEIRO DE GEOGRAFIA E ESTATÍSTICA. Produção agrícola municipal. Disponível em http://www.sidra.ibge.gov.br/bda/agric. Acesso em 5 de abril de 2010.

21. INSTITUTO DE TERRAS E PLANEJAMENTO AGRÍCOLA DO ESTADO DA PARAÍBA - INTERPA. Mesorregião do Agreste Paraibano; Microrregião do Curimataú Ocidental. Portaria/GAB/PRESI/№ 010/08. Define as áreas de circunscrição das atividades dos núcleos Regionais de Araruna, Alagoinha, Teixeira, Catolé do Rocha, Piancó, conforme anexo I a esta portaria. Diário Oficial, Cabedelo, 17 Março 2008.

22. LACERDA, C.F.; CAMBRAIA, J.; CANO, M.A.O.; RUIZ, H.A. Plant growth and solute accumulation and distribution in two sorghum genotypes under $\mathrm{NaCl}$ stress. Revista Brasileira de Fisiologia Vegetal, v.13, n.3, p.270-284, 2001.

23. LACERDA, C.F.; CAMBRAIA, J.; CANO, M.A.O.; RUIZ, H.A.; PRISCO, J. T. Solute accumulation and distribution shoot and leaf development in two sorghum genotypes under salt stress. Enviromental and Experimental Botany, v. 49, p. 107-120, 2003.

24. LIMA, C. J. G. S.; OLIVEIRA, F. A.; MEDEIROS, J. F.; OLIVEIRA, M. K. T.; ALMEIDA JÚNIOR, A. B. Resposta do feijão caupi à salinidade da água de irrigação. Revista Verde de Agroecologia e Desenvolvimento Sustentável, v. 2, n. 2, p. 79-86, 2007.

25. MACEDO, J. P. S. Desempenho do maracujazeiro amarelo irrigado com água salina, em função do espaçamento, cobertura do solo e poda da haste principal. Areia, 2006. Trabalho de Conclusão de Curso- Centro de Ciências Agrárias-Universidade Federal da Paraíba, 2006.

26. MEZA, N.; ARIZALETA, M.; BAUTISTA, D. Efecto de la salinidade em la germinación y emergência de semillas de parchita (Passiflora edulis f. flavicarpa). Revista de la Facultad de Agronomia, v. 24, n. 1, p. 69-80, 2007.

27. MUNNS, R. Comparative physiology of salt and water stress. Plant Cell Environ., v. 25, p. 239250, 2002.

28. RICHARDS, L. A. Diagnosis and improvement of saline and alkaline soils. Washington: United States Salinity Laboratory Staff. 1954. 160 p. (Agriculture, 60)

29. RODOLFO JUNIOR, F.; CAVALCANTE, L. F.; BURITI, E. S. Crescimento e produção do maracujazeiro-amarelo em solo com biofertilizantes e adubação mineral com NPK. Caatinga, v. 22, n. 2, p. 149-160, 2009.

30. SANTOS, A. C. V.; AKIBA, F. Biofertilizantes líquidos: uso correto na agricultura alternativa. Seropédica: UFRRJ, 1996, 35 p. 
31. SANTOS, G. D. Avaliação do maracujazeiro-amarelo sob biofertilizantes aplicados ao solo na forma líquida. Areia, 2001. Dissertação de mestrado em Manejo de Solo e Água- Centro de Ciências Agrárias-Universidade Federal da Paraíba, 2001.

32. SANTOS, H. G.; JACOMINE, P. K. T.; ANJOS, L. H. C.; OLIVEIRA, V. A.; OLIVEIRA, J. B.; COELHO, M. R.; LUMBREBAS, J. F.; CUNHA, T. J. F. (ed). Sistema brasileiro de classificação de solos. $2^{a}$ ed. Rio de Janeiro: Embrapa Solos. 2006. 306 p.

33. SILVA, G. F.; CAVALCANTE, L. F.; GHEYI, H. R.; ALVES, J. C. A.; COSTA, A. P. M.; PEREIRA, W. E.; OLIVEIRA, F. H. T. Comportamento do maracujazeiro amarelo em solo salino com esterco bovino líquido fermentado. Recife: Workshop Manejo e Controle da Salinidade na Agricultura Irrigada, 2007.

34. SOARES, F. A.; GHEYI, H. R.; VIANA, S. B. A.; UYEDA, C. A.; FERNANDES, P. D. Water salinity and initial development of yellow passion fruit. Scientia Agricola, v. 59, n. 3, p. 491-497, 2002.

35. SOUSA, G. B. ; CAVALCANTE, L. F. ; CAVALCANTE, I. H. L. ; BECKMAN, M. Z. C. ; NACIMENTO, J. A. M. Salinidade do substrato contendo biofertilizante para a formação de mudas de maracujazeiro irrigado com água salina. Caatinga, v. 21, p. 172-180, 2008.

36. WAHOME, P. K.; JESCH, H. H.; GRITTNER, I. Mechanisms of salt stress tolerance in two rose rootstocks: Rosa chinensis Major and R. rubiginosa. Scientia Horticulturae, v. 87, p. 207-216, 2001.

37. ZHU, J. K. Plant salt tolerance. Plant Science, v. 6, n. 2, 2001. 